\title{
STRUCTURAL SAFETY IN WOODEN BEAMS UNDER THERMAL AND MECHANICAL LOADING CONDITIONS
}

\author{
E.M.M. FONSECA, D.C.S. COELHO \& L.M.S. BARREIRA \\ Department of Applied Mechanics, Polytechnic Institute of Bragança, Portugal.
}

\begin{abstract}
The main objective of this paper is to identify different analytical methods which permit the calculation of the stress level in wooden simply supported beams, due to mechanical and thermal loading conditions. Two different wood species, with different cross-sections, will be presented. The fire resistance, the charring depth layer and the charring rate will be determined using the finite element method with Ansys ${ }^{\circledR}$ program. To characterize the stress state in wooden beams, all elements are subjected to mechanical load considering the reduction of the cross-section, influenced by thermal action. Another purpose of this work is to identify the ultimate safe load-bearing capacity in wooden beams, subjected to uniform load simultaneously with the thermal effect. All numerical results permit the specification of simple design calculation methods, simplifying the verification of the fire safety of wooden beams.

Keywords: charring depth, fire, load-bearing capacity, uniform load, wooden beam.
\end{abstract}

\section{INTRODUCTION}

Wood is a renewable resource, recently attracting public attention, as an environmentally friendly material. This product is a building material with attractive attributes such as architectural and structural characteristics. Wood is classified in two different botanical terms. The botanical terms, softwoods and hardwoods, indicate the basic structure and cell type of moisture within the tree. Softwoods generally come from the coniferous species (pines, firs and spruces, for example) and are generally fine textured. Hardwoods (eucalypts and oaks, for example) have broad leaves and the texture ranges from fine to coarse. The types of wood include softwoods, hardwoods and glued laminated woods, in the forms of solid wood, plywood and wood-based panels. Due to large variation, type and wood quality, a system of strength classes was established. Each grade of classification is a function of the physical and wood properties. The wood when exposed to accidental actions, such as fire conditions, presents a surrounding charring layer. However, this layer can delay the heating process from the exposed side to the wood core section, acting as an insulating layer. The wood core section may remain at low temperatures, depending on the fire exposure and element size therefore. It is important to calculate the value of charring rate and determine the thickness of char layer formation through the section. These parameters are important in fire safety design because they determine the residual load-bearing cross-section, due to critical external conditions. Safety rules and guidelines should be useful for different wooden structures. The high vulnerability of wood, with respect to fire, requires a rigorous thermal and mechanical analysis. The study of fire resistance of wood structures is therefore a topic of great interest. Several researchers have presented experimental and numerical models for the study of wood in the presence of high temperatures [1-3]. The charring rate of softwood or hardwood material, exposed to fire conditions, has been studied in different countries, [4-11]. Some empirical models for charring rate calculation have been developed by other researchers [4-6].

The wood species considered in this work are the Fir subalpine and Redwood, from Northern Europe. These conifer species are widely used in construction, textile, paper-making, resin 
production and applicable to engineering construction in general, being used as structural elements such as beams or columns, or in lamellar form.

This work describes the fire performance in structural wooden beams. It intends to compile design formulas for further discussions and enhancements to structural safety of wooden beams under thermal and mechanical loading conditions. The authors of this work have published different articles in conferences and journals related to this theme [12-15]. They studied other wood species to analyze the evolution of charring rate using experimental and numerical methods.

The main objectives of this work are:

- Evaluate the thermal and mechanical performance of wood, when subjected to elevated temperatures due to the simulation of a fire situation;

- Present simulation models for the analysis of the behavior of typical cross-sections when subjected to the presence of fire;

- Determine the charring layer of two different species of wood;

- Determine the mechanical resistance in a wide range of selected profiles and installed stresses arising on the basis of the residual cross-section;

- Present a set of simple calculation methods for simply supported beams, under the effect of a distributed load, considering the residual cross-section;

- Determine the ultimate load-bearing capacity of simply supported beams, as a function of load level.

\section{STRENGHT OF WOOD AT HIGH TEMPERATURES}

The most important factors for the calculation of the structural strength in wooden elements subjected to fire are the thermal degradation and the charring depth formation. The wood density decreases with the material degradation caused by the pyrolysis process, in the presence of high temperatures. The pyrolysis process usually starts for wood temperatures of $280^{\circ} \mathrm{C}$ to $300^{\circ} \mathrm{C},[16]$. The charred area has no effective resistance, producing a reduction in the resistance of the effective cross-section. On the other hand, the charring depth depends on the time of fire exposure. The verification of these parameters contributes to the assessment of their load-bearing capacity. Wood exhibits an exceptional load-bearing capacity under fire when compared with other traditional materials, such as steel and concrete. Not including the connections in the structure, where the protection at high temperatures should have particular attention, a proper cross-section size in wooden elements ensures the stabilization time to fire, without demanding special protection systems. According to Eurocode 1 (2002) [17], the evolution of fire temperature over time may be defined by standard fire curves. In this work the standard ISO834 fire curve was adopted.

\subsection{Thermal and mechanical properties}

The fire behavior of wood structures requires uncoupled thermal and mechanical analysis which is strongly dependent of the corresponding material properties. Wood burns leading to material degradation and decomposition. The wood thermal properties are strongly affected by temperature and moisture content levels. The thermal behavior of wood depends on species, but has been well documented. Eurocode 5 (2003) [18] provides the design values for the thermal properties of wood, as shown in Fig. 1, for density, thermal conductivity and specific heat. The values below $350^{\circ} \mathrm{C}$ represent the properties of wood, and above $350{ }^{\circ} \mathrm{C}$ 


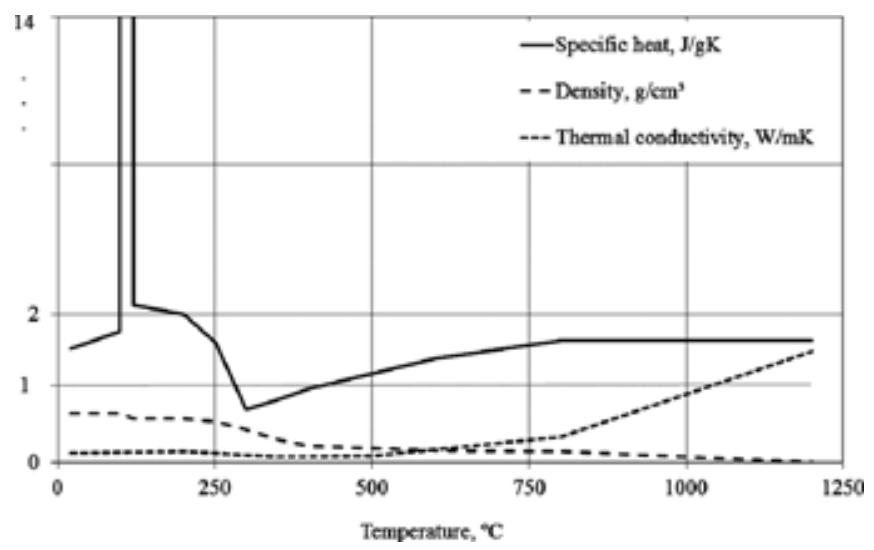

Figure 1: Thermal properties of wood elements.

Table 1: Mechanical properties and elastic ratios for two species [20].

\begin{tabular}{lcccccccccc}
\hline \multirow{2}{*}{ Species } & $\sigma_{\text {máx }}$ & $\mathrm{E}_{\mathrm{L}}$ & & & & & & & & \\
& $\mathrm{MPa}$ & $\mathrm{MPa}$ & $\mathrm{E}_{\mathrm{T}} / \mathrm{E}_{\mathrm{L}}$ & $\mathrm{E}_{\mathrm{R}} / \mathrm{E}_{\mathrm{L}}$ & $\mathrm{G}_{\mathrm{LR}} / \mathrm{E}_{\mathrm{L}}$ & $\mathrm{G}_{\mathrm{LT}} / \mathrm{E}_{\mathrm{L}}$ & $\mathrm{G}_{\mathrm{RT}} / \mathrm{E}_{\mathrm{L}}$ & $\mu_{\mathrm{LR}}$ & $\mu_{\mathrm{LT}}$ & $\mu_{\mathrm{RT}}$ \\
\hline Fir subalpine & 40.00 & 10300 & 0.039 & 0.102 & 0.070 & 0.058 & 0.006 & 0.341 & 0.332 & 0.437 \\
Redwood & 42.40 & 9200 & 0.089 & 0.087 & 0.066 & 0.077 & 0.011 & 0.360 & 0.346 & 0.373 \\
\hline
\end{tabular}

represent the properties of charred layer. The wood species considered in this study are Fir subalpine and Redwood and the value of density is equal to $460 \mathrm{~kg} / \mathrm{m}^{3}$ and $520 \mathrm{~kg} / \mathrm{m}^{3}$, respectively.

Wood is a complex composite material and is generally anisotropic, heterogeneous and porous. Mechanical properties depend upon grain orientation, and are also affected by moisture content, [19]. The mechanical behavior of wood varies with temperature when subjected to an accidental situation, as is the case of a fire. The increase of temperature influences the progressive degradation of mechanical material properties. Apart from reducing of the cross-section, the degradation of mechanical properties contributes to the loss of structuralbearing capacity. The Eurocode 5 (2003) considers a reduction of mechanical properties in the order of $20 \%$ compared to the same material at room temperature. Wood may be described as an orthotropic material, with their mechanical properties described relative to the three mutually orthogonal axes: longitudinal, radial and tangential, influenced by grain direction $[16,19,20]$. The longitudinal axis $\mathrm{L}$ is parallel to the wood fiber, the radial axis $\mathrm{R}$ is normal to the growth rings, and the tangential axis $\mathrm{T}$ is perpendicular to the grain but tangent to the growth rings, [20]. The material was considered with moisture content level to $12 \%$ and the mechanical properties are presented in Table 1 [1]. The three moduli of elasticity, which are denoted by $\mathrm{E}_{\mathrm{L}}, \mathrm{E}_{\mathrm{R}}$ and $\mathrm{E}_{\mathrm{T}}$, respectively, are the elastic moduli along the longitudinal, radial and tangential axes of wood; three moduli of rigidity, $G_{L R}, G_{L T}$ and $G_{R T}$ in the LR, LT and RT planes; and Poisson's ratios in the same planes, where the first letter of the subscript refers to direction of applied stress and the second refers to the direction of lateral deformation, [20]. 
Table 2: Moduli of elasticity and rigidity as functions of temperature [20].

\begin{tabular}{|c|c|c|c|c|c|c|c|c|}
\hline \multirow[b]{2}{*}{ Species } & \multirow[b]{2}{*}{$\mathrm{T},{ }^{\circ} \mathrm{C}$} & \multirow[b]{2}{*}{$\mathrm{K}$} & \multicolumn{3}{|c|}{ Moduli of elasticity, MPa } & \multicolumn{3}{|c|}{ Moduli of rigidity, $\mathrm{MPa}$} \\
\hline & & & EL & ET & ER & GLR & GLT & GRT \\
\hline & 20 & 1.00 & 10300 & 401.7 & 1050.6 & 721 & 597.4 & 61.8 \\
\hline \multirow[t]{3}{*}{ Fir subalpine } & 100 & 0.50 & 5150 & 200.85 & 525.3 & 360.5 & 298.7 & 30.9 \\
\hline & 300 & 0.01 & 103 & 4.02 & 10.51 & 7.21 & 5.97 & 0.62 \\
\hline & 20 & 1.00 & 9200 & 818.8 & 800.4 & 607.2 & 708.4 & 101.2 \\
\hline \multirow[t]{2}{*}{ Redwood } & 100 & 0.50 & 4600 & 409.4 & 400.2 & 303.6 & 354.2 & 50.6 \\
\hline & 300 & 0.01 & 92 & 8.19 & 8 & 6.07 & 7.08 & 1.01 \\
\hline
\end{tabular}

Table 3: Maximum tensile and compressive strength [18].

\begin{tabular}{lrccc}
\hline Species & & & $\begin{array}{c}\text { Compressive } \\
\sigma_{\max (\mathrm{T})}, \mathrm{MPa}\end{array}$ & $\begin{array}{c}\text { Tensile } \\
\sigma_{\max (\mathrm{T})}, \mathrm{MPa}\end{array}$ \\
\hline \multirow{4}{*}{ Fir subalpine } & 20 & 1.00 & 40.00 & 68.00 \\
& 100 & 0.50 & 20.00 & 34.00 \\
& 300 & 0.01 & 0.40 & 0.68 \\
Redwood & 20 & 1.00 & 42.40 & 69.00 \\
& 100 & 0.50 & 21.20 & 34.50 \\
& 300 & 0.01 & 0.424 & 0.69 \\
\hline
\end{tabular}

The mechanical properties of wood are affected by the temperature. The orthotropic properties are determined according to the temperature-dependent reduction factor $K$ in Eurocode 5 (2003), Tables 2 and 3.

The mechanical strength of both species is defined in Table 3 according to Eurocode 5 (2003). The strength decreases faster for temperatures up to $100^{\circ} \mathrm{C}$ and decreases slowly for temperature between $100^{\circ} \mathrm{C}$ and $300^{\circ} \mathrm{C}$.

The coefficient of thermal expansion is a measure of the relative change of dimension caused by temperature change and is influenced by the orientation of the grain. In tests of both hardwoods and softwoods, the parallel-to-grain values have ranged from about 3.1 to $4.5 \times 10^{-6}{ }^{\circ} \mathrm{C}^{-1}$ and from 21.6 to $39.4 \times 10^{-6}{ }^{\circ} \mathrm{C}^{-1}$ across the grain, [16]. In this work a value of thermal expansion equal to $3.1 \times 10^{-6}{ }^{\circ} \mathrm{C}^{-1}$ was considered, [19].

\section{CASE STUDIES}

This study considers two species of softwood, origin of northern Europe and marketed in Portugal: Fir subalpine and Redwood. To standardize the characteristics of these woods, different datasheets of several companies have been consulted. Table 4 shows the main standard dimensions considered in this work, where B is the initial breadth and D is the member depth.

\subsection{Thermal resistance of wooden sections}

A nonlinear and transient thermal analysis was carried out using the general purpose finite element software Ansys ${ }^{\circledR}$. A two-dimensional finite element with eight nodes (PLANE77) 
Table 4: Different standard sizes.

\begin{tabular}{|c|c|c|c|c|c|}
\hline & & \multicolumn{2}{|c|}{ Fir subalpine } & \multicolumn{2}{|c|}{ Redwood } \\
\hline & & $\mathrm{B}, \mathrm{mm}$ & $\mathrm{D}, \mathrm{mm}$ & $\mathrm{B}, \mathrm{mm}$ & $\mathrm{D}, \mathrm{mm}$ \\
\hline & \multirow{5}{*}{ D } & 230 & 350 & 90 & 50 \\
\hline & & 250 & 350 & 175 & 50 \\
\hline & & 300 & 350 & 225 & 50 \\
\hline & & 230 & 250 & 90 & 75 \\
\hline & & 250 & 250 & 175 & 75 \\
\hline \multirow{4}{*}{\multicolumn{2}{|c|}{$\triangle \quad \mathrm{B} \longrightarrow$}} & 300 & 250 & 225 & 75 \\
\hline & & 230 & 100 & 90 & 105 \\
\hline & & 250 & 100 & 175 & 105 \\
\hline & & 300 & 100 & 225 & 105 \\
\hline
\end{tabular}

was used. All cross-sections considered in Table 4 were modeled and 36 simulations were performed, with fire exposure on three or four sides.

The time history of the temperature field was calculated during one hour of fire exposure. One objective is to determine the char layer thickness versus time for different sections exposed to fire. The boundary conditions considered in all analysis were convection and radiation, according to the temperature evolution in fire. The evolution of fire temperature over time was defined by standard fire curve ISO834. The convection coefficient used for surfaces directly exposed to fire was considered equal to $25 \mathrm{~W} / \mathrm{m}^{2} \mathrm{~K}$, according to Eurocode 1 (2002). Eurocode 5 (2003) proposes the value of emissivity in wood material equal to 0.8 . The charring layer thickness is determined by the results obtained through monitoring and recording the temperature threshold value of $300^{\circ} \mathrm{C}$. The boundary layer that limits the wood cold core was defined according to Eurocode 5 (2003).

The following images in Fig. 2 present the numerical results associated with the temperature profiles in the range from $20^{\circ} \mathrm{C}$ to $300^{\circ} \mathrm{C}$; the thickness of the layer which is the ash is the depth carbonized, in which there were temperature records above $300^{\circ} \mathrm{C}$. The charring depth layer thickness is represented by $(b)$ in the tangential direction and $(d)$ in the vertical direction. The calculation of the charring rate, results from the ratio of charring depth to the time of fire exposure, represented through $\beta_{\mathrm{b}}$ and $\beta_{\mathrm{d}}$, respectively in Fig. 2.

The charring rate and the residual area after fire exposure were determined. The average of charring rate $\beta_{n}$ was calculated for each studied profile based on values of $\beta_{b}$ and $\beta_{d}$. The residual wood cross-section for each standard size $\mathrm{B} \times \mathrm{D}$ was obtained for different time of fire exposure, as represented in Tables 5 and 6. The residual area (Ar) was obtained as the difference between the initial cross-section and the charring depth effect, and it is represented as a percentage of the initial cross-section area (A). Based on all numerical results for calculating the charring depth, the average charring rate $\beta_{n}$ for each fire exposure was determined, as represented in Tables 5 and 6.

The typical values for charring rate of wood varies between 0.5 and $1.0 \mathrm{~mm} / \mathrm{min}$. Eurocode 5 (2003) allows the use of simplified and advanced methods for the calculation of the amount of charring depth layer. This method is a conduction model based on thermal properties of wood. According to Eurocode 5 (2003), the proposed formula to calculate the 


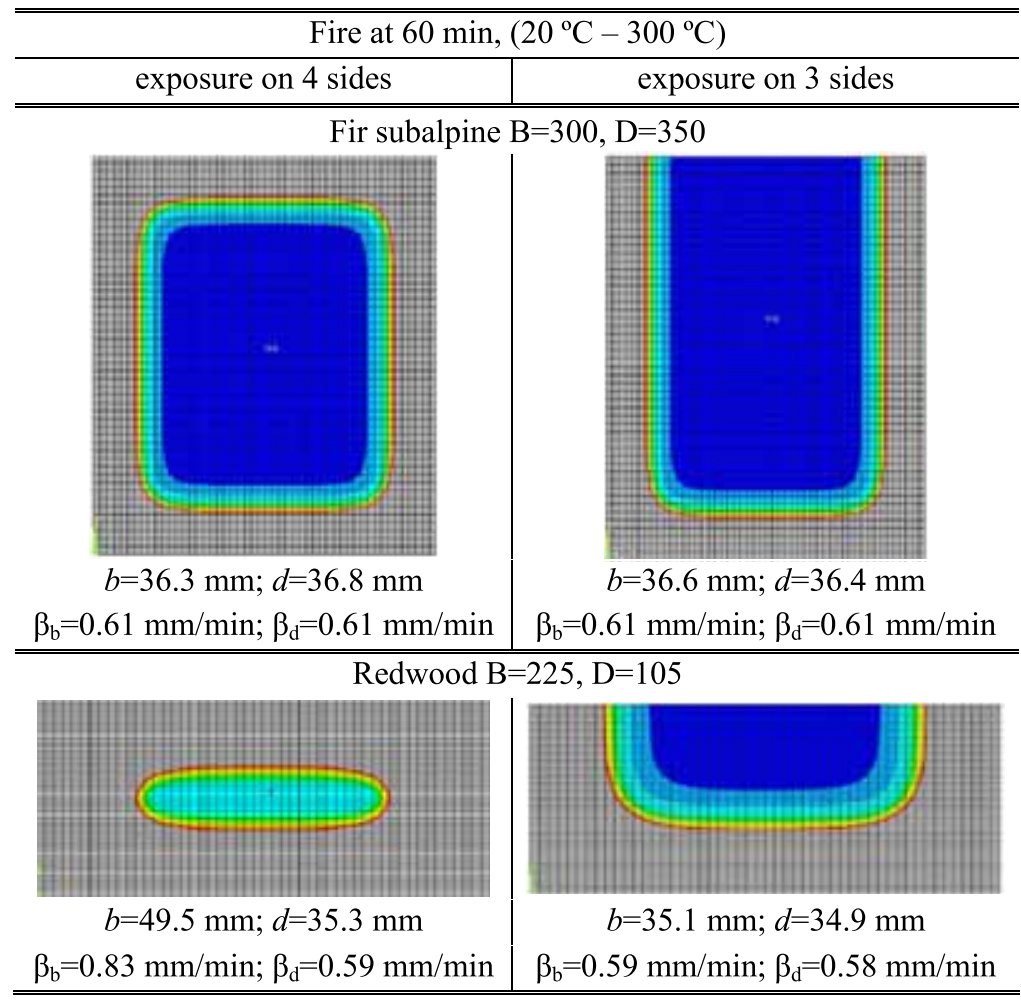

Figure 2: Mesh of the cross-section and thermal numerical results.

Table 5: Residual area $(\mathrm{Ar}=\% \mathrm{~A})$, Fir subalpine.

\begin{tabular}{lllllll}
\hline & & \multicolumn{2}{c}{ Fire on 3 sides } & & \multicolumn{2}{c}{ Fire on 4 sides } \\
\cline { 3 - 4 } \cline { 6 - 7 } $\mathrm{B}$ and $\mathrm{D}, \mathrm{mm}$ & & \multicolumn{2}{c}{30 and $60 \mathrm{~min}$} & & \multicolumn{2}{c}{30 and $60 \mathrm{~min}$} \\
\hline 230 & 350 & $78 \%$ & $61 \%$ & & $74 \%$ & $54 \%$ \\
250 & 350 & $80 \%$ & $63 \%$ & & $75 \%$ & $55 \%$ \\
300 & 350 & $82 \%$ & $68 \%$ & & $77 \%$ & $60 \%$ \\
230 & 250 & $77 \%$ & $58 \%$ & & $70 \%$ & $48 \%$ \\
250 & 250 & $78 \%$ & $60 \%$ & & $71 \%$ & $49 \%$ \\
300 & 250 & $80 \%$ & $64 \%$ & & $74 \%$ & $53 \%$ \\
230 & 100 & $66 \%$ & $42 \%$ & & $49 \%$ & $10 \%$ \\
250 & 100 & $68 \%$ & $44 \%$ & & $50 \%$ & $11 \%$ \\
300 & 100 & $70 \%$ & $47 \%$ & & $52 \%$ & $13 \%$ \\
\hline \multicolumn{2}{l}{ Charring rate $\beta_{n}, \mathrm{~mm} / \mathrm{min}$} & 0.65 & 0.62 & & 0.66 & 0.70 \\
\hline
\end{tabular}


Table 6: Residual area $(\mathrm{Ar}=\% \mathrm{~A})$, Redwood.

\begin{tabular}{|c|c|c|c|c|c|}
\hline \multirow{2}{*}{\multicolumn{2}{|c|}{$\mathrm{B}$ and $\mathrm{D}, \mathrm{mm}$}} & \multicolumn{2}{|c|}{ Fire on 3 sides } & \multicolumn{2}{|c|}{ Fire on 4 sides } \\
\hline & & \multicolumn{2}{|c|}{30 and $60 \mathrm{~min}$} & \multicolumn{2}{|c|}{30 and $60 \mathrm{~min}$} \\
\hline 90 & 105 & $47 \%$ & $5 \%$ & $35 \%$ & $0 \%$ \\
\hline 90 & 75 & $43 \%$ & $0 \%$ & $22 \%$ & $0 \%$ \\
\hline 175 & 105 & $64 \%$ & $40 \%$ & $50 \%$ & $13 \%$ \\
\hline 90 & 50 & $34 \%$ & $0 \%$ & $0 \%$ & $0 \%$ \\
\hline 225 & 105 & $69 \%$ & $46 \%$ & $54 \%$ & $18 \%$ \\
\hline 175 & 75 & $61 \%$ & $30 \%$ & $37 \%$ & $0 \%$ \\
\hline 225 & 75 & $63 \%$ & $36 \%$ & $40 \%$ & $0 \%$ \\
\hline 175 & 50 & $49 \%$ & $10 \%$ & $0 \%$ & $0 \%$ \\
\hline 225 & 50 & $52 \%$ & $15 \%$ & $0 \%$ & $0 \%$ \\
\hline \multicolumn{2}{|c|}{ Charring rate $\beta_{n}, \mathrm{~mm} / \mathrm{min}$} & 0.63 & 0.69 & 0.67 & 0.71 \\
\hline
\end{tabular}

Table 7: Comparison of charring rate $\beta_{n} \mathrm{~mm} / \mathrm{min}$.

\begin{tabular}{lccc}
\hline & \multicolumn{2}{c}{ Ansys® } & \\
\cline { 2 - 3 } Species & Fire exposure on 3 sides & Fire exposure on 4 sides & Eurocode 5 (2003) \\
\hline Fir subalpine & 0.64 & 0.68 & 0.65 \\
Redwood & 0.66 & 0.69 & 0.65 \\
\hline
\end{tabular}

charring depth, when exposure to fire is in more than one direction, depends on the charring rate used for unprotected surfaces, according to:

$$
d_{\text {char }, n}=\beta_{n} t
$$

where $d_{c h a r, n}$ is the charring depth layer in $\mathrm{mm}, \beta_{n}$ is the design charring rate under standard fire exposure in $\mathrm{mm} / \mathrm{min}$ and $t$ is the time of fire exposure in min.

Table 7 compares the obtained numerical charring rate with a constant value proposed by Eurocode 5 (2003). The obtained charring rate is higher when fire exposure is on four sides and for Redwood species.

Eqn (2) should be used for the calculation of the effective charring depth layer, according to Eurocode 5 (2003):

$$
a_{e f}=a_{c h a r, n}+/ \times \kappa_{0}, \mathrm{~mm}
$$

where $k_{0}$ is a function of the duration of fire exposure. For unprotected surfaces, and time exposure less than $20 \mathrm{~min}, k_{0}=1$; when time is greater and equal to $20 \mathrm{~min}, k_{0}$ is equal to $k_{0}=t / 20$.

Figures 3, 4, 5, 6 represent different graphs, with an original formula, which permit the determination of the residual area $(\% \mathrm{Ar})$ due time exposure $(t, \mathrm{~min})$ in all wood species 


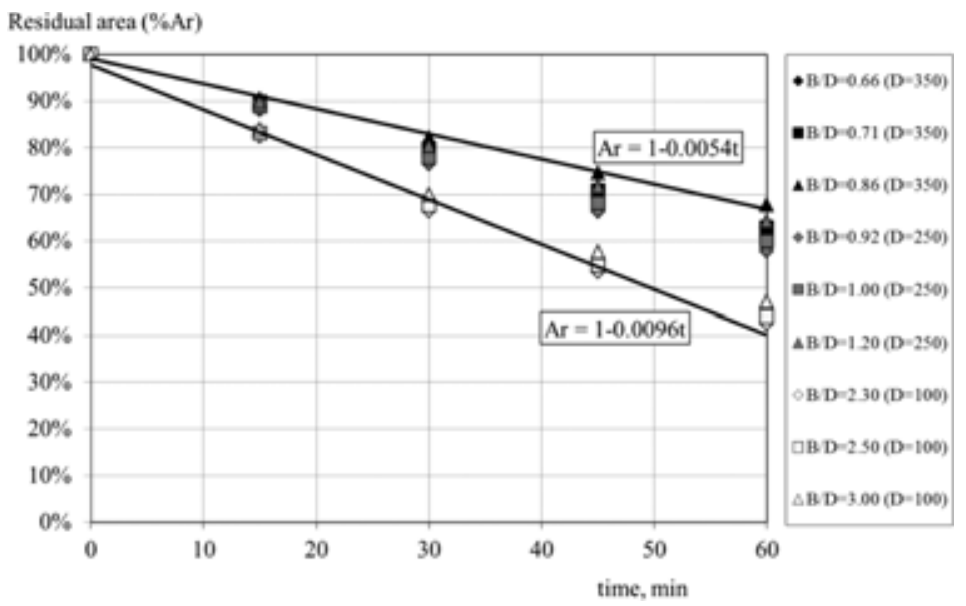

Figure 3: Fire exposure on three sides, Fir subalpine.

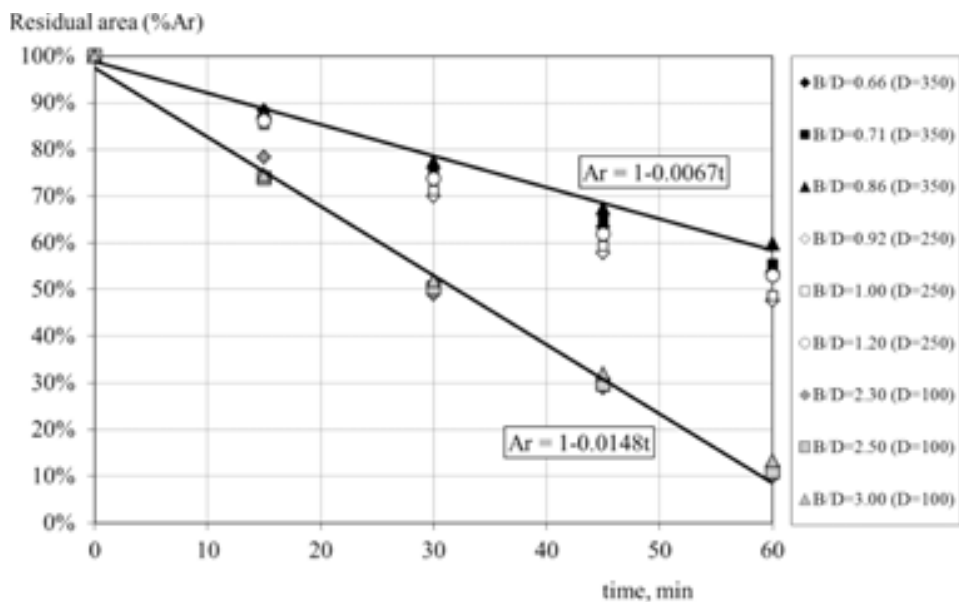

Figure 4: Fire exposure on four sides, Fir subalpine.

considered in Table 4. In all graphs a linear tendency line was obtained according to the maximum and the minimal values represented.

The studied profiles in Fig. 3 present a resistant area greater than $40 \%$ when exposed to fire on three sides.

In Fig. 4 when fire exposure increases, the resistant area decreases. For the same time of fire exposure the slender profiles have less strength.

Some of Redwood profiles were able to resist only $45 \mathrm{~min}$ of fire exposure, when exposed to three sides.

The fire exposure of Redwood species on four sides is more critical. After $30 \mathrm{~min}$ of fire exposure, all profiles have a reduction greater than $50 \%$ of the resistant cross-section. Crosssections in Redwood have less resistance when compared with Fir subalpine. Fir subalpine has a cross-section which resists for one hour of fire exposure on three sides, with a residual 


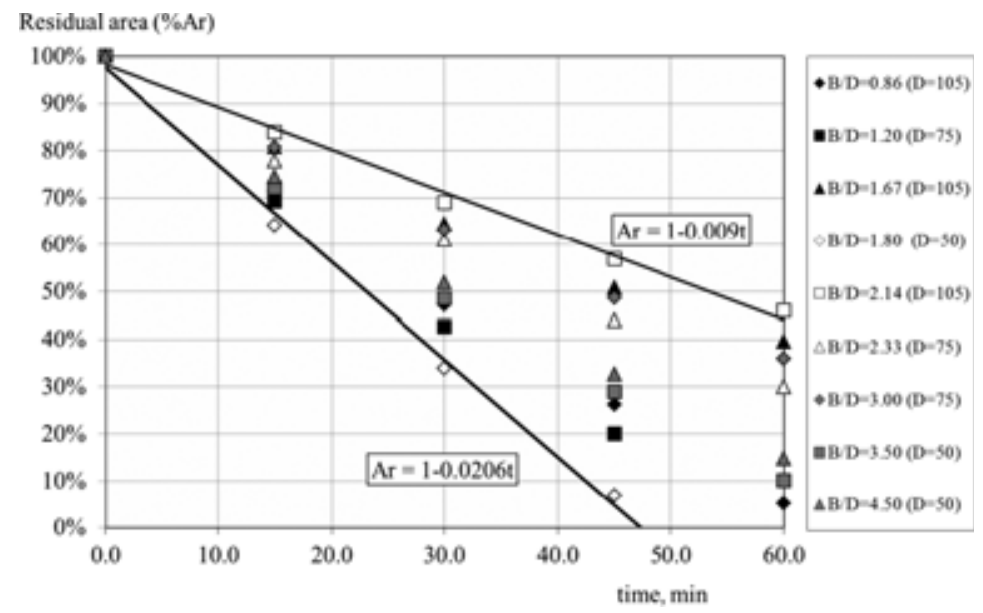

Figure 5: Fire exposure on three sides, Redwood.

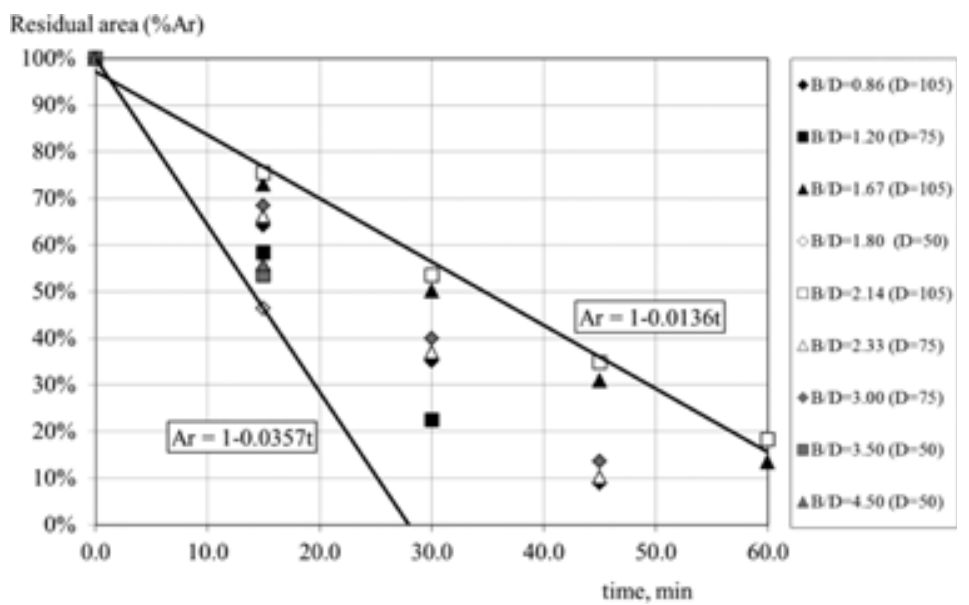

Figure 6: Fire exposure on four sides, Redwood.

area around $70 \%$. In all profiles the residual area on three sides is comparatively higher to fire exposure on four sides.

3.2 Thermal and mechanical resistance in wooden beams

A structural and linear finite element analysis using temperature data from thermal analysis was used to study different wooden beams, simply supported and subjected to a uniform loading, as shown in Fig. 7. Three-dimensional finite solid elements (SOLID185) with eight nodes were used in Ansys ${ }^{\circledR}$ program for the mechanical analysis. The total length of the wooden beam is equal to $3 \mathrm{~m}$ and the value of the uniform load is equal to $0.5 \mathrm{kN} / \mathrm{m}$.

Longitudinal maximum stresses were calculated in all beam elements using orthotropic material properties. Figure 8 shows the numerical results obtained for two different species 

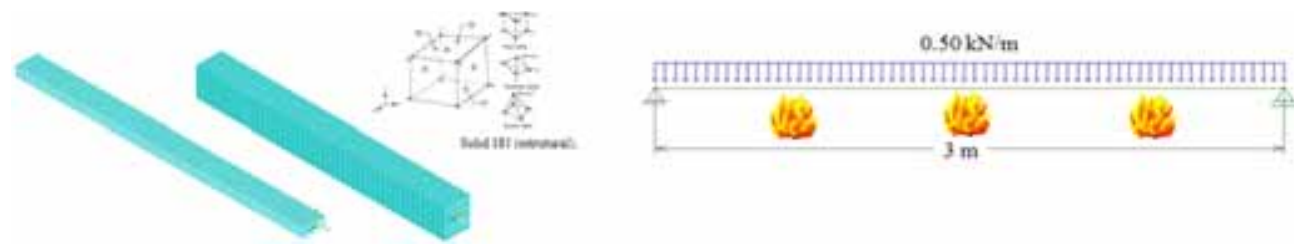

Figure 7: Solid mesh for the simply supported beam.

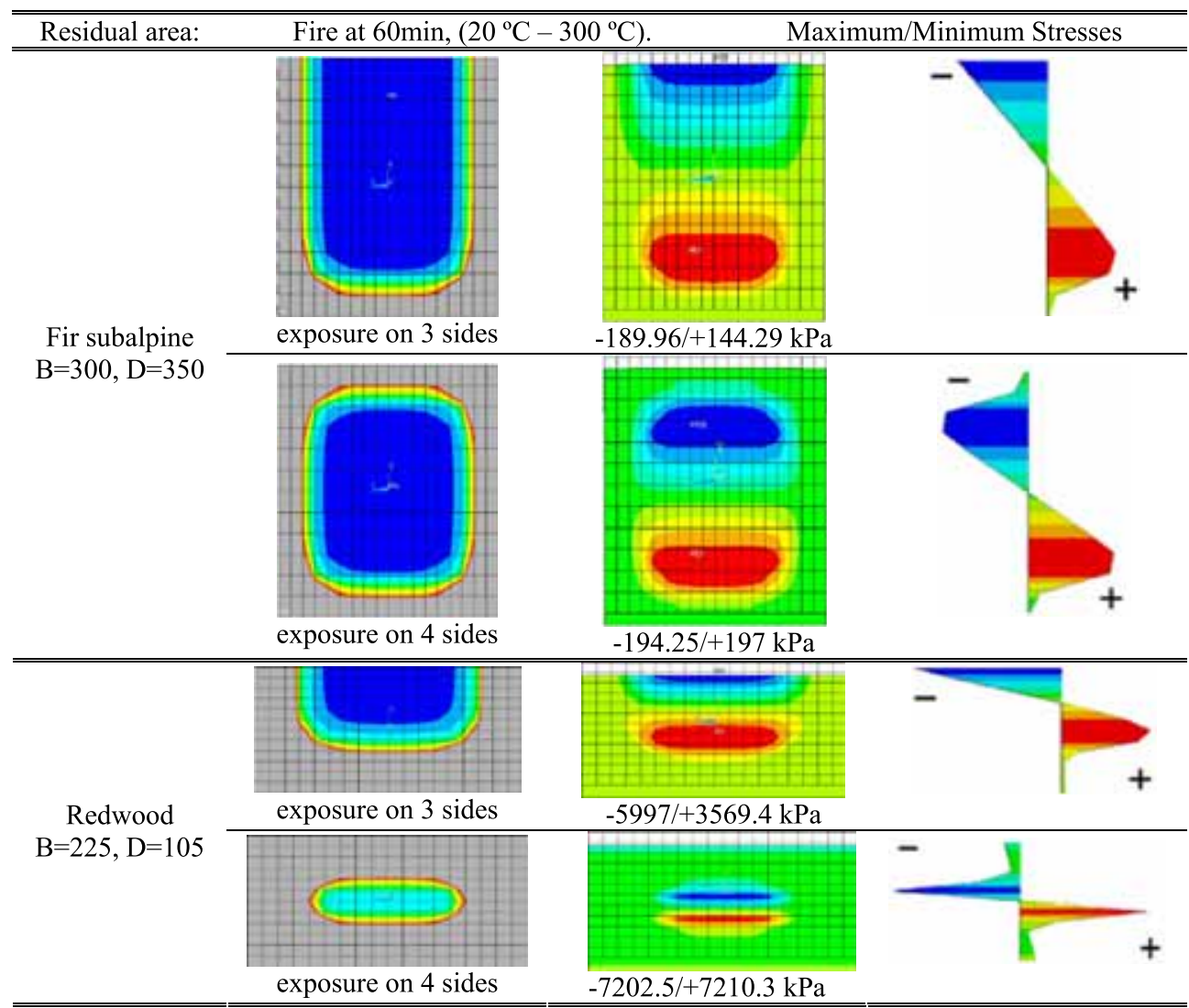

Figure 8: Mesh of cross-section and numerical results at mid-span of the wooden beam.

of wooden beams. The first column represents the resistant area obtained for $60 \mathrm{~min}$ of fire exposure. The second and third columns represent the maximum and minimum stress at mid cross-section of the wooden beam, as the result of the thermal and mechanical loading combination.

The longitudinal stress distribution is linear through the cold section, but decreases quickly in the charring layer. For three sides of fire exposure, the neutral axis diverges from the original position, by about a value equal to one half of the charring depth. For this condition, the maximum longitudinal stress occurs due to compression. When fire exposure is on four sides, the neutral axis remains unchangeable. Analytical and standard formula were provided 
for the bending stress calculation in wooden beams, simply supported with fire exposure in three or four sides and a uniform load. In these equations the moment of inertia is affected by the charring depth layer, reducing the initial cross-section size of the beam. Analytical equations could be used to further the progress and validation of computational modeling tools in predicting the fire performance of wood-based constructions.

\subsection{Structural safety in wooden beams}

For assessing the safety of wooden beams, a structural nonlinear finite element analysis was implemented, using temperature data from thermal analysis and an incremental and iterative solution method. The same three-dimensional finite solid element (SOLID185) was used with eight nodes and three degrees of freedom at each node. Various plots were obtained with the value of the ultimate load-bearing capacity $(W)$, as shown in Figs. 9-12. All curves are functions of fire exposure time during one hour for wooden beams considering fire on three or four sides. For each fire condition an exponential regression was obtained which permits the calculation of ultimate uniform load-bearing capacity in wooden beams subjected to fire conditions, in three or four sides. In these graphs the solution is presented for two different cross-sections $(B=250 \mathrm{D}=350 ; \mathrm{B}=300 \mathrm{D}=350)$ and $(\mathrm{B}=175 \mathrm{D}=105 ; \mathrm{B}=225 \mathrm{D}=105)$ for Fir subalpine and Redwood species, respectively. In this study, the selected cross-sections present higher fire resistance, as presented in Tables 5 and 6.

Figures 9 and 10 represent the ultimate uniform load-bearing capacity for Fir subalpine. The ultimate load-bearing capacity of this wooden specie is higher for three sides of fire exposure in comparison to four sides. All graphs represent different exponential formulas which permit the calculation of the load-bearing capacity in different time instants.

Figures 11 and 12 represent the solution for the ultimate load-bearing capacity for Redwood. All cross-sections studied are less fire resistant than Fir subalpine. As shown, the ultimate load-bearing capacity is around 10 times less than that for the same cross-sections in Fir subalpine.

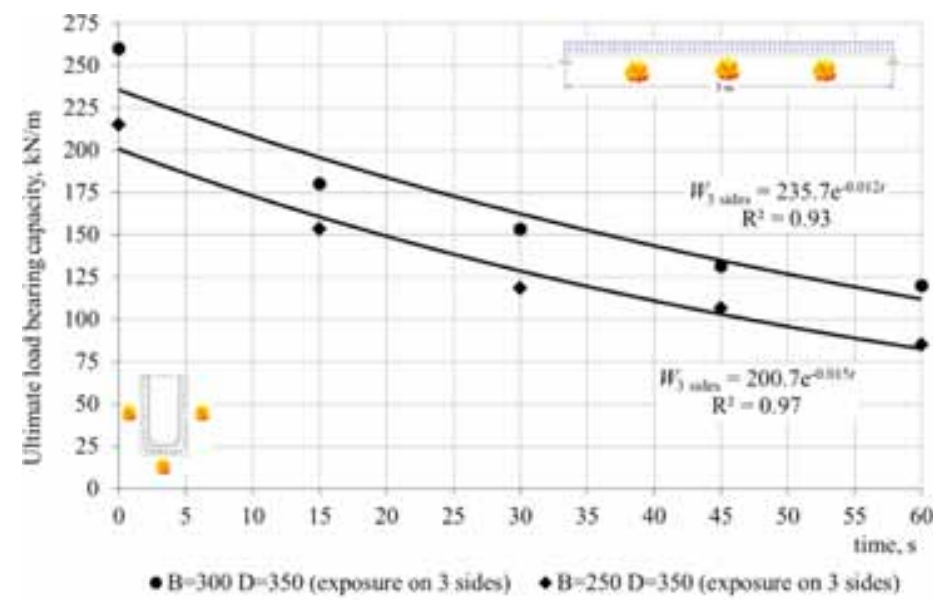

Figure 9: Ultimate load-bearing capacity for fire exposure on three sides, Fir subalpine. 
The assessment of the ultimate load bearing in fire condition is presented for both species. Failure can occur when the full strength cold core sections are no longer capable of supporting the load. Simple analytical formulas are presented to determine the ultimate load-bearing capacity (3) and 4 . These formulas should be used for future recommendations in wooden beams simply supported and exposed to fire, function of mechanical strength and residual section area.

$$
\begin{gathered}
W_{\text {exposure on } 3 \text { sides }}^{\text {ultimg }}=\frac{\sigma_{\max (T)} \times 4\left(B-2 d_{e f}\right)\left(D-d_{e f}\right)^{2}}{3 \times L^{2}} \\
W_{\text {exposure on } 4 \text { sides }}^{\text {ultimate load bearing }}=\frac{\sigma_{\max (T)} \times 4\left(B-2 d_{e f}\right)\left(D-2 d_{e f}\right)^{2}}{3 \times L^{2}}
\end{gathered}
$$

where $W$ is the ultimate uniform load bearing, $\sigma_{\max (T)}$ is the maximum strength of the wood material at a fire temperature, $L$ is the effective length of beam, $B$ is the breadth of member before exposure to fire, $D$ is the depth of member before exposure to fire and $d_{e f}$ is the charring depth.

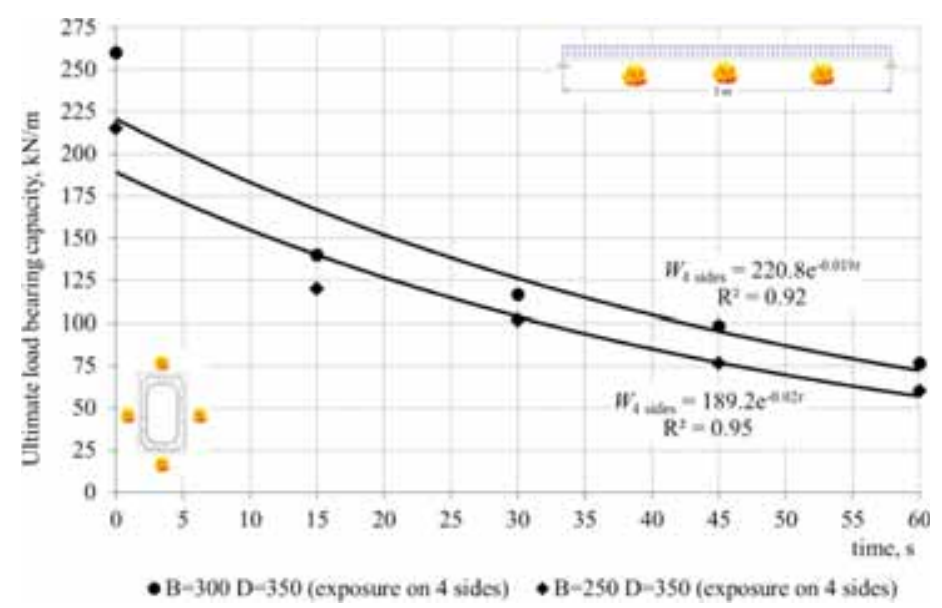

Figure 10: Ultimate load-bearing capacity for fire exposure on four sides, Fir subalpine.

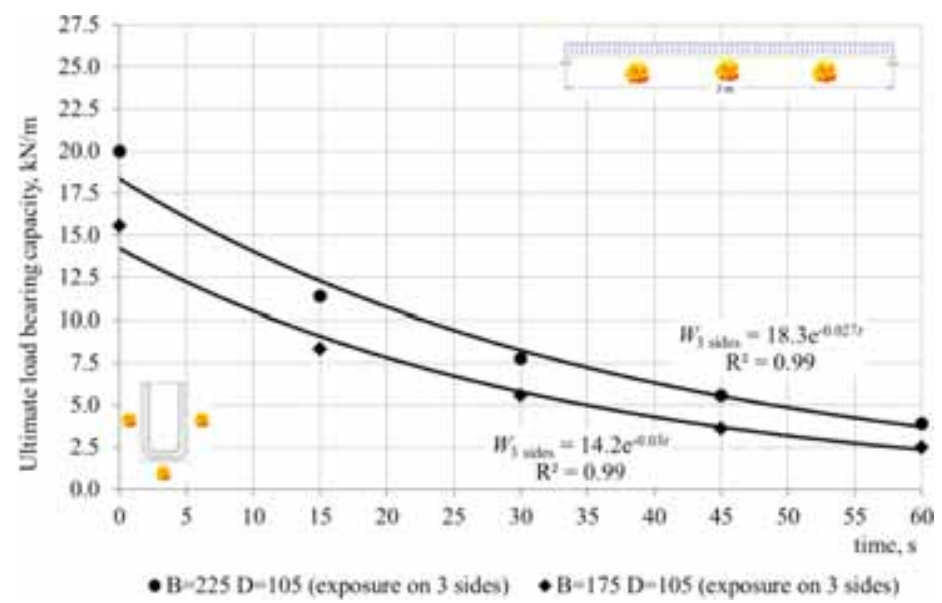

Figure 11: Ultimate load-bearing capacity for fire exposure on three sides, Redwood. 


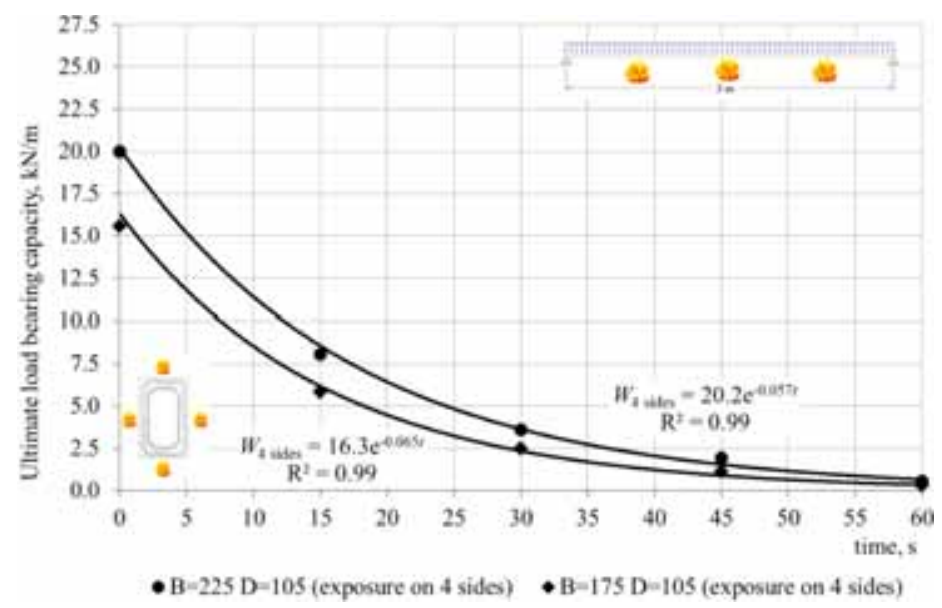

Figure 12: Ultimate load-bearing capacity for fire exposure on four sides, Redwood.

Also the obtained numerical results agree with the values derived from these formulas. Using the simple calculation method (formulas (3) and (4) to wooden beams) it was found that the imposed maximum distributed load, decreases with decreasing the resistance of the profile cross-section under the thermal effect. After one hour of fire exposure, Fir subalpine species suffers a reduction of $50 \%$ in the ultimate load-bearing capacity. For Redwood, the behavior is more critical, since all studied cross-sections hardly withstand any mechanical load when exposed to fire for one hour.

\section{CONCLUSIONS AND FUTURE WORK}

In this work the structural fire performance of wooden beams was estimated using the finite element method. The cross-sections made of Fir subalpine present higher fire resistance than Redwood species. High temperatures reduce the dimensions of wood cross-sections, as the strength and the stiffness of the heated affected zone. The stress decreases quickly in the charring layer. When fire exposure is on three sides, neutral axis diverges from the original position but remains unchangeable with fire on four sides. Wood exposed to fire will decompose to provide an insulating charred layer that retards further degradation.

In this work, simple design formulas were presented to facilitate the assessment of fire resistance and the resistant area of simply supported wood beams. These formulas could be used to verify the proper cross-section size in wooden elements that ensures a stabilization time to fire, without demanding special protection systems.

Future developments in this area should consider the experimental validation, perform the same study for other type of loading and supporting conditions, study the behavior of wood in tubular sections subjected to the fire action and study the behavior of wood protected with insulation material.

\section{REFERENCES}

[1] White, R.H. \& Dietenberger, M.A., Fire safety (Chapter 17). Wood Handbook: Wood as an Engineering Material, Forest Products Laboratory, USDA Forest Service, 1999.

[2] Poon, L. \& England, J.P., Literature Review on the Contribution of Fire Resistant Timber Construction to Heat Release Rate - Timber Development Association, Warrington Fire Research Aust. Pty. Ltd., Project No.20633, version 2b, pp. 1-78, 2003. 
[3] Janssens, M.L., Modeling of the thermal degradation of structural wood members exposed to fire. Fire and Materials, 28, pp. 199-207, 2004. doi: http://dx.doi. org/10.1002/fam.848

[4] Schaffer, E.L., Charring Rate of Selected Woods Transverse to Grain. Research paper FPL 69 Forest Products Laboratory: Madison (WI), 1967.

[5] White, R.H., Charring Rates of Different Wood Species. PhD dissertation, Madison University of Wisconsin, Madison (WI), 1988.

[6] White, R.H., Erik, V. \& Nordheim, E.V., Charring rate of wood for ASTM E119 exposure. Fire Technol, 28(1), pp. 5-30, 1992. doi: http://dx.doi.org/10.1007/BF01858049

[7] Konig, J. \& Walleij, L., One-Dimensional Charring of Timber Exposed to Standard and Parametric Fires in Initially Unprotected and Postprotection Situations. Swed Inst Wood Technol Res, 1999.

[8] Gardner W.D. \& Syme, D.R. Charring of Glued-Laminated Beams of Eight AustralianGrown Timber Species and the Effect of $13 \mathrm{~mm}$ Gypsum Plasterboard Protection on their Charring. N.S.W. Technical report no.5, Sydney, 1991.

[9] Collier, P.C.R., Charring Rates of Timber, Study report, Branz: New Zealand, 1992.

[10] Pun, C.Y., Seng, H.K., Midon, M.S. \& Malik, A.R., Timber Design Handbook. FRIM, Malayan Forest Records no.42, 1997.

[11] Cachim, P.B. \& Franssen, J.M., Assessment of Eurocode 5 charring rate calculation methods. Fire Technology, 46, pp. 169-181, 2010. doi: http://dx.doi.org/10.1007/ s10694-009-0092-x

[12] Fonseca, E.M.M. \& Barreira, L., Charring rate determination of wood pine profiles submitted to high temperatures. Third International Conference on Safety and Security Engineering, Vol. 108, eds M. Guarascio, C.A. Brebbia, F. Garzia, WIT Press: Italy, pp. 449-457, 2009.

[13] Fonseca, E.M.M. \& Barreira, L.M.S., Metodo experimental para determinacao da espessura carbonizada na madeira quando submetida a altas temperaturas. Revista Portuguesa de Engenharia de Estruturas RPEE, 7, pp. 33-40, 2010.

[14] Fonseca, E.M.M. \& Barreira, L., High temperatures in parallel or perpendicular wood grain direction: a numerical and experimental study. WIT Press, Fourth International Conference on Safety and Security Engineering IV, eds. M. Guarascio, G. Reniers, C.A. Brebbia, F. Garzia, Belgium, 117, pp. 171-183, 2011.

[15] Fonseca, E.M.M. \& Barreira, L., Experimental and numerical method for determining wood char-layer at high temperatures due an anaerobic heating. International Journal of Safety and Security Engineering, 1(1), pp. 65-76, 2011. doi: http://dx.doi.org/10.2495/ SAFE-V1-N1-65-76

[16] Gandhi, PD. \& Backstrom, R., Thermal and Mechanical Finite element modelling of Wood-Floor Assemblies Subjected to Furnace Exposure. Project number: 07CA42520, Underwriters Laboratoires, USA, 2008.

[17] EN 1991-1-2:2002. Eurocode 1: Actions on Structures - Part 1-2: General actions Actions on Structures Exposed to Fire, CEN, 2002.

[18] EN 1995-1-2:2004. Eurocode 5: Design of timber structures, Part 1-2: GeneralStructural fire design, CEN, 2004.

[19] Winady, J. \& Rowell, R., Chapter 11. Chemistry of Wood Strength. Handbook of Wood Chemistry and Wood Composites, CRC Press LLC, pp. 303-347, 2005.

[20] Green, D.W., Winandy, J.E. \& Kretschmann, D.E., Mechanical Properties of Wood, ch04, Wood Handbook Wood as an Engineering Material, Forest Products Laboratory USDA Forest Service: Madison, Wisconsin, 1999. 